\title{
Covid-19 infection in cancer patients: the management in a diagnostic unit
}

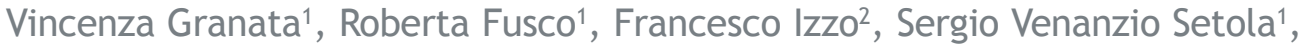 \\ Michele Coppola ${ }^{3}$, Roberta Grassi ${ }^{4}$, Alfonso Reginelli ${ }^{4}$, Salvatore Cappabianca ${ }^{4}$, \\ Roberto Grassi ${ }^{4,5}$, Antonella Petrillo



Radiol Oncol 2021; 55(2): 121-129.

Received 17 September 2020

Accepted 19 December 2020

Correspondence to: Roberta Fusco, M.D., Radiology Division, Istituto Nazionale Tumori Fondazione Pascale, Naples, Italy. E-mail: r.fusco@istitutotumori.na.it

Disclosure: No potential conflicts of interest were disclosed.

Background. COVID-19 infection is particularly aggressive in frail patients, as cancer patients. Therefore, the more suitable management of the oncological patient requires a multidisciplinary assessment, to identify which patients should be treated, as inpatients or outpatients, and which treatments can be procrastinated.

Conclusions. The role of radiologist is crucial, and, all cancer patients who need an imaging evaluation will need to be studied, using the most appropriate imaging tools related to the clinical question and paying a special attention to preserve public health. Guidelines are necessary in the correct organization of a radiology unit to manage patients with suspected or confirmed COVID-19 infection, and whenever possible, a satellite radiography center with dedicated equipment should be used to decrease the transmission risk.

Key words: COVID-19 infection; cancer patients, diagnostic unit; management; guideline

\section{Introduction}

In December 2019, health authorities in Wuhan, China, identified a cluster of acute respiratory disease of unknown etiology. ${ }^{1}$ Subsequently the researchers identified a new viral agent, SARS-CoV-2, as responsible for the heart of an international outbreak centred on Hubei. On 30 January 2020, World Health Organization (WHO) confirmed the COVID-19 epidemic as a public health emergency and on 11 March 2020 demarcated the rapid spread of infection as a pandemic in the world. ${ }^{1,2}$ Globally, at the time of writing (15 September 2020), there have been $29,525,571$ confirmed cases of COVID-19, including 934,192 deaths. In Italy, there have been 289,990 confirmed cases, including 35,633 deaths, reported to $\mathrm{WHO} .^{2}$ According to the data reported by the Italian authorities, the fatality rates, related to COVID-19 infection, increase exponentially after the age of 70 years, and the presence of an oncological pathology increases the risk of mortality. ${ }^{3}$ According to Liang et al., cancer patients have a higher risk of getting COVID-19 infection. ${ }^{4}$ This data may be correlated to a higher rate of screening, higher risks for nosocomial contaminations and decreased immune defence. Moreover, the rate of pulmonary complications, requiring resuscitation, is higher in cancer patients than in non-cancer patients ( $39 \%$ vs. $8 \%$ ), especially when a treatment was performed in the months before the infection. ${ }^{4}$ During epidemic of COVID-19, a guideline for the optimal management of oncological patients urgently needs and the cancer patients should be treated as outpatients if possible 
at the nearest medical centre. ${ }^{5}$ Conversely, patients who need to be hospitalized for oncological therapies should have COVID-19 infection excluded prior being admitted and more attention should be paid to COVID-19 symptoms identification and of adverse reactions caused by the malignancy or antitumor treatments. ${ }^{5}$ However, an intentional postponing of antitumor treatment should be considered according to patient performance status. ${ }^{5}$ Therefore, the more suitable management of the cancer patient requires a multidisciplinary assessment, to identify which patients should be treated, as inpatients or outpatients, and which treatments can be procrastinated. It is clear that in this decision the role of radiologist is primary, for a correct staging of the disease as well as for identifying complications from radio- or chemo- therapy. Therefore, in this pandemic condition, all cancer patients who need an imaging evaluation will still need to be studied, using the most appropriate imaging tools related to the clinical question and taking attention to preserve public health.

\section{Methods}

This document is based upon oncological panel of expert opinions by 9 radiologists, 1 cancer surgeon, and 1 radiotherapist, as well as additional expert in statistic. The panel included members of Italian Society of Radiology and Interventional Radiology (SIRM), including the President, the oncology diagnostic imaging section president-elect and the SIRM board. The panel identified four possible scenarios on how to manage a cancer patient during the COVID-19 pandemic in a radiology unit. The entire panel was convened during a single session using a live audio and video interface. The four scenarios were presented, discussed, and refined. These scenarios are intended to support the management of adults only. Children merit separate consideration and are beyond the scope of this document.

We accorded to the "Grading of Recommendations Assessment, Development and Evaluation (GRADE) basic approaches and rules, and particularly considered experts' evidence to assess the quality of a body of evidence to make recommendations. The level of evidence was categorized as "high quality", "moderate quality", "low quality", or "very low quality". Recommendations were classified as "strong" or "weak". The strong recommendation does not always mean there is sufficient intervention effectiveness. Besides the effectiveness of intervention, the forming of recommendations is based on the severity of the disease, patient willingness, safety, and economics". "Once the evidence has been identified and assessed, recommendations were formulated based on the evidence by a face-to-face meeting of panel members and supplemented by experts participating in the panel meeting" ${ }^{6}$

The document derived also by a comprehensive literature search. Using the following terms "COVID-19 OR SARS-CoV 2" AND "Cancer Patients" AND "Management" and "Imaging" we found a total of 148 articles published between Dec $1^{\text {st }}, 2019$ and Sept 15 th, 2020 . Each article was evaluated for relevance to the primary endpoint and a summary of key findings from relevant articles was created. The panel assessed 39 papers that met the document criteria. ${ }^{7-46}$

\section{Overview of clinical scenarios}

Four scenarios can be defined in the radiological management of cancer patient:

1. Non-COVID-19 cancer patient

2. Suspected COVID-19 cancer patient

3. Confirmed COVID-19 cancer patient

4. Cancer Patients with incidental COVID-19 diagnosis

Although each scenario requires different management, however all should be performed with the intent of avoiding contamination for health workers and other patients.

\section{First scenario: non COVID-19 cancer patient}

Patients, with laboratory non confirmed COVID-19 infection by using reverse transcriptase-polymerase chain reaction (RT-PCR) test of nasopharyngeal swab to SARS-CoV-2, are defined as non COVID-19 patients. However, since laboratory tests are not yet used as a screening tool to identify COVID-19 patients, and many people may be asymptomatic or pauci-symptomatic it would be appropriate for health professionals to consider all patients as potential infected. ${ }^{7}$ Therefore, according to Jin et al. ${ }^{7}$, all patients should wear N95 (strong recommendation) or surgical mask (weak recommendation), although the Centers for Disease Control and Prevention recommend that patients wear a facemask which can also be just a cloth mask, it is appropriate that a cancer patient, because he is fragile, should wear at least one surgical mask. In addition, while waiting for a radiological procedure, 
TABLE 1. Recommendations for first scenario - non COVID-19 cancer patient, according to Italian Society of Radiology and Interventional Radiology (SIRM) guidelines ${ }^{10}$

\begin{tabular}{|c|c|}
\hline Patients & Health care staff \\
\hline $\begin{array}{l}\text { Wear } \\
\text { - N95 mask [strong recommendation] } \\
\text { - or surgical mask [weak recommendation] }\end{array}$ & $\begin{array}{l}\text { Wear } \\
\text { - N95 mask [strong recommendation] } \\
\text { - goggles or face shield [strong recommendation] } \\
\text { - gloves [strong recommendation] } \\
\text { - surgical cap [weak recommendation] } \\
\text { shoe covers [weak recommendation] }\end{array}$ \\
\hline $\begin{array}{l}\text { Stay away from other people } \\
\text { (at least } 6 \text { feet of distance) } \\
\text { [strong recommendation] }\end{array}$ & $\begin{array}{l}\text { Clean and disinfect with } 500 \mathrm{mg} / \mathrm{L} \text { chlorine-containing } \\
\text { disinfectant the radiological equipment used, clean their } \\
\text { hands properly, and the room should be opened for } \\
\text { appropriate ventilation [strong recommendation] }\end{array}$ \\
\hline
\end{tabular}

the patient should stay away from other people (at least 6 feet of distance). The family members, accompanying patient, should follow the same recommendations.

The healthcare staff should wear N95 mask, avoids direct contact with patient's secretions, especially oral or respiratory, wear goggles or face shield, wear gloves, wash or disinfect hands before wearing gloves and after removing the gloves. A surgical cap and shoe covers may be added. After each radiological procedure, the community hospital should clean and disinfect with $500 \mathrm{mg} / \mathrm{L}$ chlorine-containing disinfectant the radiological equipment used, clean their hands properly, and the room should be opened for appropriate ventilation. The isolation times of the section in which the person has stayed depend on the number of air parts insured for the environment (about 6/h with related 69 minutes of isolation), according to SIRM guidelines (Table 1). ${ }^{7-10}$

\section{Second scenario: suspected covid-19 cancer patient}

Suspected infected patient should be isolated, controlled, and diagnostic confirmation should be as quick as possible. Patients with mild symptoms should remain in home isolation, while patients with severe symptoms should be hospitalized, following the isolation guidelines. ${ }^{7}$ As for the first scenario, also in this case patient and healthcare staff should follow the same procedures concerning the use of masks, wear goggles or face shield, gloves and the distance of at least 6 feet if possible, avoiding direct contact with respiratory secretions, so as disinfection procedures for radiological equipment and rooms. In this scenario, it asks the radiologist to confirm the diagnosis of COVID-19. COVID-19 diagnosis is made by RT-PCR test, however radiological test is suggested for medical triage of suspected patients with moderate-severe clini-

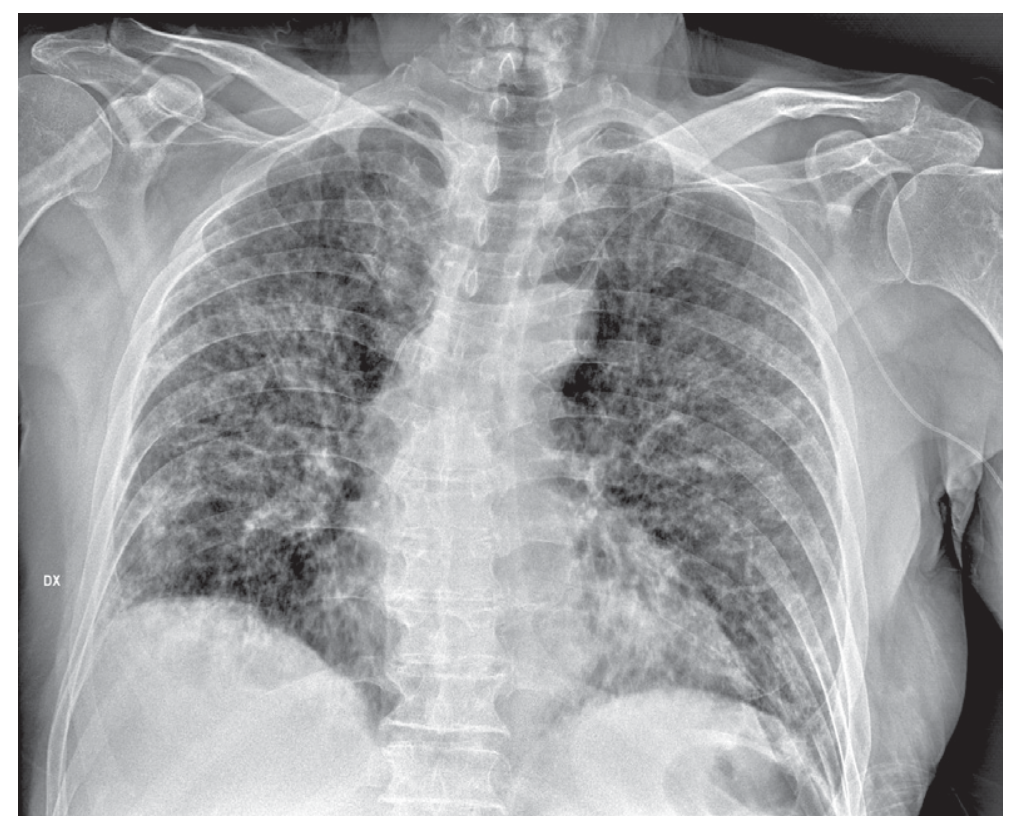

FIGURE 1. Man, 64 year. Chest $x$-ray shows patchy consolidation and strip-like opacities in a patient with confirmed COVID-19 infection by reverse transcriptasepolymerase chain reaction (RT-PCR).

cal symptoms and with higher pre-test infection probability. ${ }^{8}$ The reported sensitivity of chest $\mathrm{x}$-ray (CXR) for COVID-19 pneumonia is relatively low in the early phase of the disease and in mild cases (69\%). ${ }^{48}$ Conversely, chest computed tomography (CT) shows greater sensitivity for early pneumonic change, disease progression, and alternative diagnoses; the administration of the intravenous contrast medium, is essential for the diagnosis of pulmonary thromboembolism. ${ }^{9}$ However, in Italy, to reduce the possibility of the spread of the infection, in accordance with the Italian Society of Radiology and Interventional Radiology (SIRM) guidelines, CXR is the first tool to be used in patients with suspected COVID-19 (see Figure 1 that shown a patchy consolidation and strip-like opacity in a 
TABLE 2. Recommendations for second scenario - suspected COVID-19 cancer patient, according to Italian Society of Radiology and Interventional Radiology (SIRM) guidelines ${ }^{10}$

\begin{tabular}{|c|c|}
\hline Patients & Healthcare staff \\
\hline \multicolumn{2}{|c|}{$\begin{array}{l}\text { Isolated, controlled, and diagnostic confirmation should } \\
\text { be as quick as possible }\end{array}$} \\
\hline $\begin{array}{l}\text { Wear } \\
\text { - N95 mask [strong recommendation] } \\
\text { - or surgical mask [weak recommendation] }\end{array}$ & $\begin{array}{l}\text { Wear } \\
\text { - } \quad \text { go5 mask [strong recommendation] } \\
\text { - goggles or face shield [strong recommendation] } \\
\text { - surgical cap [weak recommendation] } \\
\text { - shoe covers [weak recommendation] }\end{array}$ \\
\hline \multirow[t]{2}{*}{$\begin{array}{l}\text { Stay away from other people } \\
\text { (at least } 6 \text { feet of distance) } \\
\text { [strong recommendation] }\end{array}$} & $\begin{array}{l}\text { Clean and disinfect with } 500 \mathrm{mg} / \mathrm{L} \text { chlorine-containing } \\
\text { disinfectant the radiological equipment used, clean their } \\
\text { hands properly, and the room should be opened for } \\
\text { appropriate ventilation } \\
\text { [strong recommendation] }\end{array}$ \\
\hline & $\begin{array}{l}\text { Diagnostic tool } \\
\text { - Chest radiography (CXR; not very sensitive), with portable } \\
\text { equipment in the isolation room [strong recommendation] } \\
\text { - Computed tomography (CT; greater sensitivity) for early } \\
\text { pneumonic change, disease progression, and alternative } \\
\text { diagnoses; } \\
\text { the administration of the intravenous contrast medium for the } \\
\text { diagnosis of pulmonary thromboembolism }\end{array}$ \\
\hline
\end{tabular}

patient with confirmed COVID-19 disease by RTPCR). ${ }^{10}$ Since, portable equipment for performing the diagnostic investigation in the patient 's isolation room is the element that might favour CXR in selected patients, reducing the risk of COVID-19 infection and eliminating the risk related to the transport route to a CT scanner (Table 2$){ }^{8}$

\section{Third scenario: confirmed COVID-19 cancer patient}

"The COVID-19 infected patients show symptoms as fatigue, fever, dry cough, dyspnoea, with or without nasal congestion, runny nose or other upper respiratory symptoms. Patients with mild symptoms may have no signs, conversely in patients with severe symptoms, we could find breath shortness, moist rales in lungs, weakened breath sounds, dullness in percussion, and increased or decreased tactile speech tremor. During the early stage of COVID-19 disease, the leukocytes number in peripheral blood was normal or decreased and the lymphocyte count decreased. In some patients, liver enzyme, creatine kinase and myoglobin increased. In severe case, the increase of D-dimer was reported. The typical CT/CXR imaging findings were multiple, patchy, sub-segmental or segmental ground-glass opacities in both lungs. They were classified as "paving stone-like" changes by finegrid or small honeycomb-like thickening of interlobular septa. In the elderly or severe condition patients more common features are multiple, patchy or large patches



FIGURE 2. Man, 53 year. CT shows multiple focal ground-glass opacities. (A) Axial plane, (B) multiplanar reconstruction in coronal plane. 


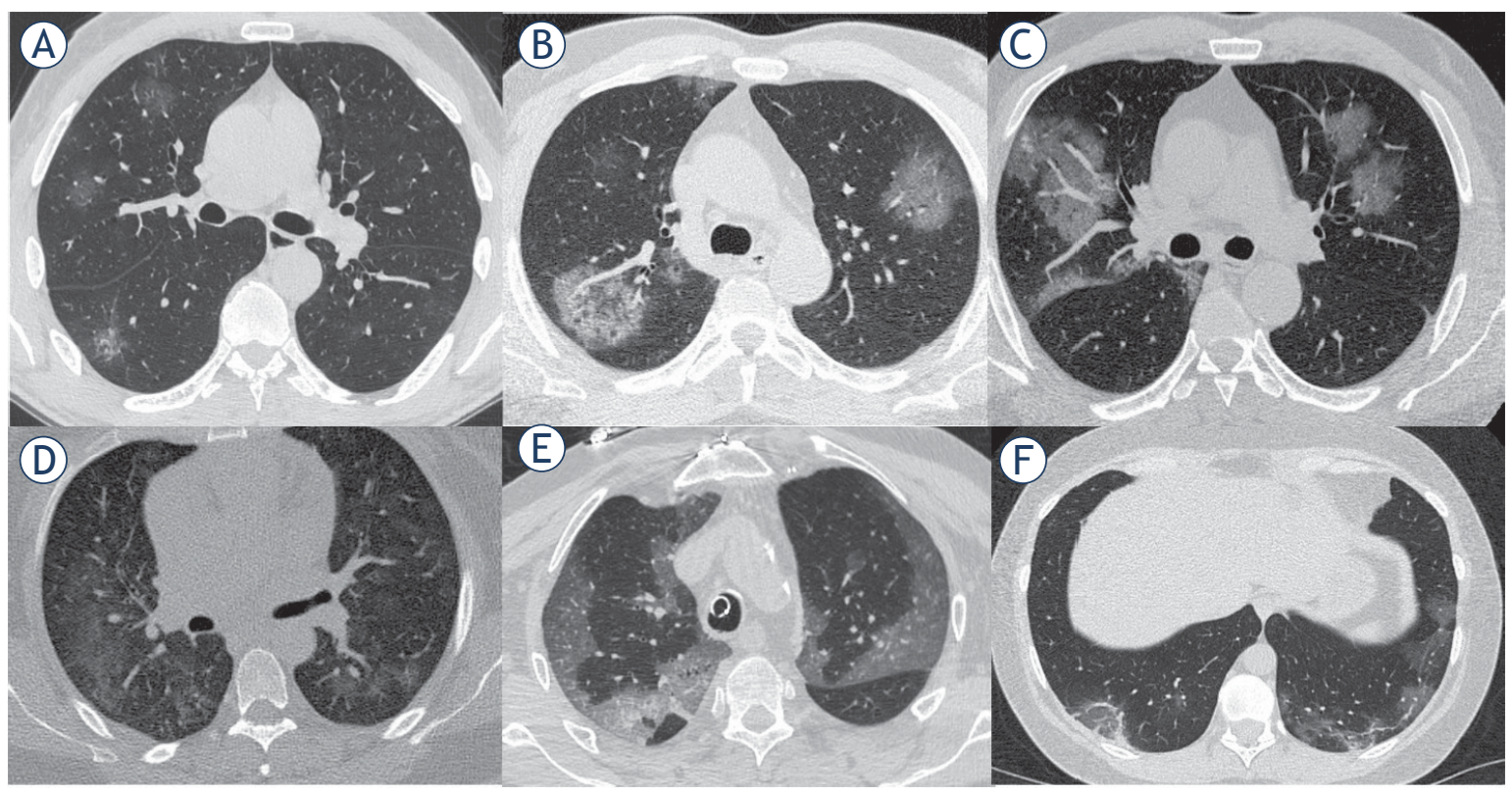

FIGURE 3. Man, 61 year. CT shows ground-glass opacities separated by thickened interlobular septa. (A-F) Axial planes.

of consolidation in both lungs, with a little grid-like or honeycomb-shaped interlobular septal thickening, especially in the middle and lower lobes. Based on CT image we find 5 stages according to the time of onset and the response of body to the virus" 7 :

1. Ultra-early stage. The stage without clinical symptoms, within 1-2 weeks after the infection. "The typical imaging features are single, double or scattered focal ground-glass opacity, nodules located in central lobule surrounded by patchy ground-glass opacities, patchy consolidation and sign of intrabronchial air-bronchogram, which was dominant in the middle and lower pleura"7 (Figure 2).

2. Early stage. One-three days after clinical manifestations. "CT scan shows single or multiple scattered patchy or agglomerated ground-glass opacities, separated by honeycomb-like or grid-like thickened of interlobular septa" 7 - crazy paving (Figure 3).

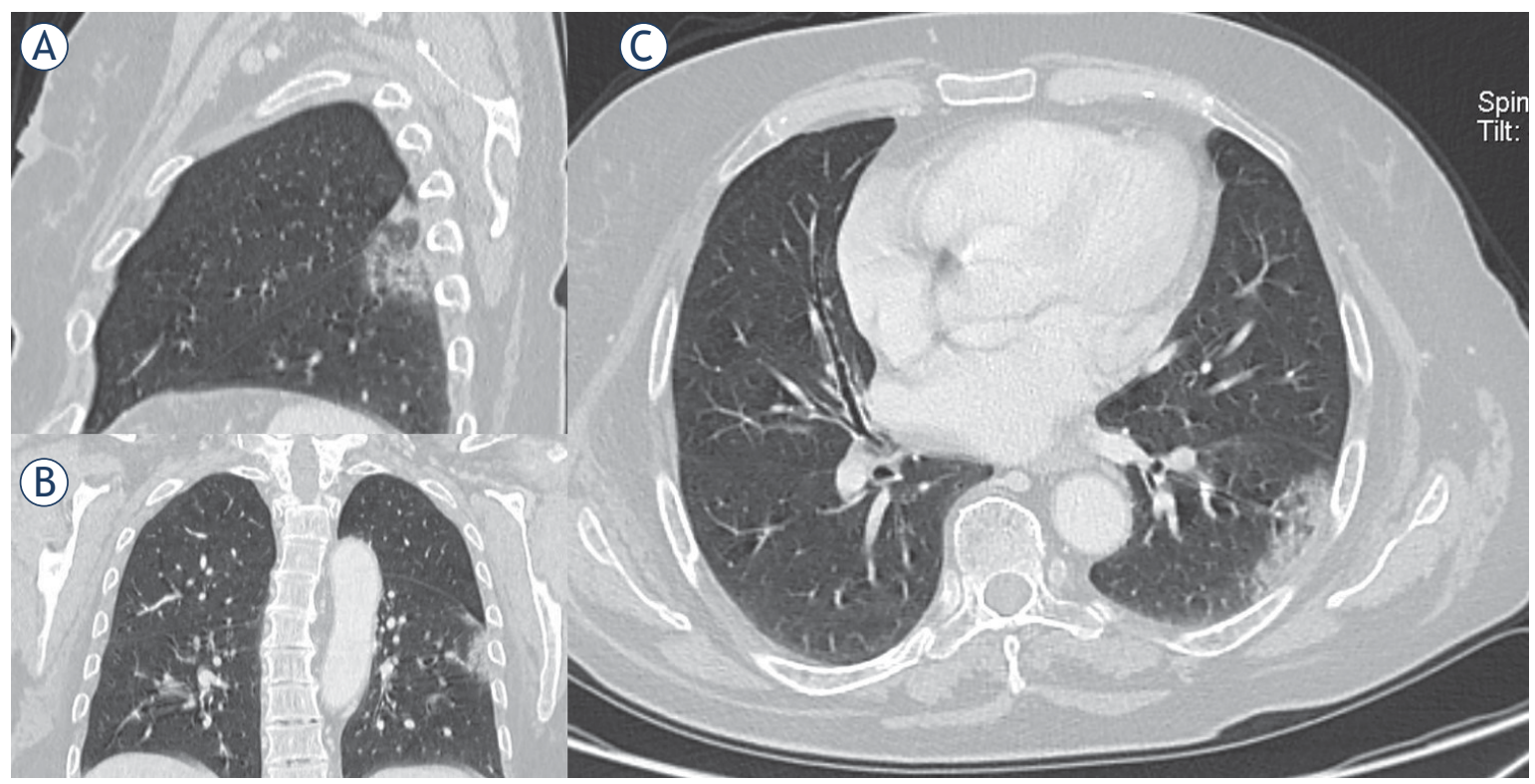

FIGURE 4. Woman, 54 year. CT shows patchy consolidation in apical segment of left lower lung. (A) Multiplanar reconstruction in sagittal plane; (B) multiplanar reconstruction in coronal plane; (C) axial plane. 
TABLE 3. Recommendations for third scenario - confirmed Covid-19 cancer patient, according to Italian Society of Radiology and Interventional Radiology (SIRM) guidelines ${ }^{10}$

\begin{tabular}{|c|c|}
\hline Patients & Healthcare staff \\
\hline $\begin{array}{l}\text { Isolated and controlled } \\
\text { - treated in designated hospitals with isolation and } \\
\text { protection conditions } \\
\text { [strong recommendation] }\end{array}$ & $\begin{array}{l}\text { Medical personnel enter into the isolation area through } \\
\text { designated channels } \\
\text { (strongrecommendation] }\end{array}$ \\
\hline $\begin{array}{l}\text { Wear } \\
\text { - } \quad \text { N95 mask [strong recommendation] } \\
\text { - or surgical mask [weak recommendation] }\end{array}$ & $\begin{array}{l}\text { Wear } \\
\text { - } \quad \text { go5 mask (strong recommendation] } \\
\text { - gloves (strong recommendation] } \\
\text { - } \quad \text { surgical cap (weak recommendation] } \\
\text { - } \quad \text { shoe covers (weak recommendation] }\end{array}$ \\
\hline \multirow[t]{2}{*}{$\begin{array}{l}\text { Stay away from other people } \\
\text { (at least } 6 \text { feet of distance) } \\
\text { [strong recommendation] }\end{array}$} & $\begin{array}{l}\text { Clean and disinfect with } 500 \mathrm{mg} / \mathrm{L} \text { chlorine-containing } \\
\text { disinfectant the radiological equipment used, clean their } \\
\text { hands properly, and the room should be opened for } \\
\text { appropriate ventilation } \\
\text { [strong recommendation] }\end{array}$ \\
\hline & $\begin{array}{l}\text { Diagnostic tool } \\
\text { - } \quad \text { daily chest radiographs are not indicated } \\
\text { infection, for defining complications and for a correct } \\
\text { differential diagnosis } \\
\text { - The chest ultrasound (POCUS - point-of-care ultrasound) a } \\
\text { monitoring tool to evaluate the effectiveness of the prono- } \\
\text { supination manoeuvres }\end{array}$ \\
\hline
\end{tabular}

3. Rapid progression stage. Three-seven days after clinical manifestations started. "CT features are a fused and large-scale light consolidation sometimes with air-bronchogram inside".

4. Consolidation stage. Seven- fourteen days after clinical symptoms appeared. "CT shows multiple patchy consolidations in slighter density and smaller range than that of the previous stage"7 (Figure 4).

5. Dissipation stage. Two and 3weeks after the onset of clinical symptoms. "CT shows patchy consolidation or strip-like opacity. As time goes on, it showed grid-like thickening of interlobular septa, thickening and strip-like twist of bronchial walls and a few scattered patchy consolidations"7 (Figure 5).

"Confirmed infected patients should be treated in designated hospitals with isolation and protection conditions. Medical personnel enter into the isolation area with proper self-protection through designated channels". ${ }^{7}$

Several features should be considered in for imaging methods in the COVID-19 patient. First, daily chest radiographs are not indicated in stable intubated patients with COVID-19, so it is possible also to reduce exposure risk of radiology technicians. ${ }^{8}$ Second, CT scan is indicated for the evaluation of the stage of infection, for defining complications and for a correct differential diagnosis. ${ }^{8}$ Third, the chest ultrasound (POCUS - point-of-care ultrasound), performed by the intensivists at the patient's bed, can also represent a monitoring tool to evaluate the effectiveness of the prono-supination manoeuvres. Systematic application of the POCUS can reduce the use of diagnostic imaging resources, also reducing staff exposure to possible contamination and helping to optimize therapies especially in critically ill patients (Table 3 ). ${ }^{10-12}$

\section{Fourth scenario: Cancer patients with incidental COVID-19 diagnosis}

We defined cancer patient with incidental COVID-19 diagnosis, when the diagnosis is random, during examination by staging or follow-up for oncological disease. CT features of COVID-19 infection are non-specific, however, the detection of these in an asymptomatic patient allows to identify that group of asymptomatic patients who can favour the spread of the infection in the community. It is reported that asymptomatic carriers of COVID-19 are $17.9 \%-33.3 \%$ of all infected cases. ${ }^{13,14}$ The undetected infected patients are responsible for a rapid spread of SARS-CoV2. ${ }^{15}$ RT-PCR test in this scenario is important to identify an occult infection and limit further transmission within the community. Therefore, although in the cancer patient, especially when undergoing immunotherapy, interstitial pneumonia may be a complication of treatment, in a pandemic phase it is essential to exclude COVID-19 infection, so that the patient, even asymptomatic, must be considered infected before laboratory tests (Table 4 ). 
TABLE 4. Fourth scenario -Cancer Patients with incidental COVID-19 diagnosis, according to Italian Society of Radiology and Interventional Radiology (SIRM) guidelines ${ }^{10}$

\begin{tabular}{|c|c|}
\hline Patients & Healthcare staff \\
\hline \multicolumn{2}{|c|}{$\begin{array}{l}\text { Controlled } \\
\text { - diagnostic confirmation should be as quick as possible } \\
\text { [strong recommendation] }\end{array}$} \\
\hline $\begin{array}{l}\text { Wear } \\
\text { - N95 mask [strong recommendation] } \\
\text { - or surgical mask [weak recommendation] }\end{array}$ & $\begin{array}{l}\text { Wear } \\
\text { - } \quad \text { gog mask [strong recommendation] } \\
\text { - gloves [strong recommendation] } \\
\text { - surgical cap [weak recommendation] } \\
\text { - shoe covers [weak recommendation] }\end{array}$ \\
\hline $\begin{array}{l}\text { Stay away from other people } \\
\text { (at least } 6 \text { feet of distance) } \\
\text { [strong recommendation] }\end{array}$ & $\begin{array}{l}\text { Clean and disinfect with } 500 \mathrm{mg} / \mathrm{L} \text { chlorine-containing } \\
\text { disinfectant the radiological equipment used, clean their } \\
\text { hands properly, and the room should be opened for } \\
\text { appropriate ventilation } \\
\text { [strong recommendation] }\end{array}$ \\
\hline
\end{tabular}


FIGURE 5. Man, 76 year. CT shows strip-like opacity, grid-like thickening of interlobular septa, thickening and strip-like twist of bronchial walls and patchy consolidations. (A) Axial plane; (B) multiplanar reconstruction in coronal plane; (C) multiplanar reconstruction in sagittal plane.

\section{Infection prevention in a radiology unit}

Up to day, it is known that the main source of COVID-19 infection are patients during the first week of infection, later the viral load diminishes and in some studies live virus was not isolated past 8th day post infection. Respiratory droplet is the main route of transmission, so as strict contact. Although, several data, as the source of the virus and its ability to spread between people is unknown, however it is clear that it is possible a human-to-human transmission. ${ }^{16}$

"For healthcare providers, the centers for disease control (CDC) groups medical-related exposures into low, medium, and high-risk" ${ }^{17}$ Within a radiology unit, a brief, without protection interaction with an infected patient, so as a prolonged close contact with a masked, are classified as low-risk exposures. ${ }^{17,18}$
However, the radiographers, since exposed continuously, might be infected to COVID-19. Therefore, guidelines are necessary in the correct organization of a radiology unit to manage patients with suspected or confirmed COVID-19 infection, and if possible, portable diagnostic equipment should be employed to reduce the patient's movements. Moreover, it would also be appropriate to use a satellite radiography centre with dedicated equipment to decrease the risk of transmission. The Centers for Disease Control and Prevention guidelines for SARS COVID-19 recommended that the healthcare staff should wear N95 mask, avoid direct contact with patient's secretions, especially oral or respiratory, wear goggles or face shield, wear gloves, wash or disinfect hands before wearing gloves and after removing the gloves. A surgical cap and shoe covers may be added. ${ }^{17,46}$ Radiological equipment, such as CT and Magnetic Resonance (MR), ultrasound probes, and image viewing station should 
be disinfected after every contact with suspected patients. Health personnel with suspicious exposure, without adequate personal protective equipment, should be observed for 14-day, starting from the last day of contact with the COVID-19 infected patients. If properly trained, the can avoid contamination of equipment, staff and other patients. ${ }^{19}$

\section{Conclusions}

COVID-19 infection is particularly aggressive in frail patients, as cancer patients. Therefore, the more suitable management of the cancer patient requires a multidisciplinary assessment, to identify which patients should be treated, as inpatients or outpatients, and which treatments can be procrastinated. It is clear that the role of radiologist is crucial, and, all cancer patients who need an imaging evaluation will still need to be studied, using the most appropriate imaging tools related to the clinical question and taking attention to preserve public health. Therefore, guidelines are necessary in the correct organization of a radiology unit to manage patients with suspected or confirmed COVID-19 infection, and whenever possible, a satellite radiography center with dedicated equipment should be used to decrease the risk of transmission.

\section{References}

1. Lake MA. What we know so far: COVID-19 current clinical knowledge and research. Clin Med 2020; 20: 124-7. doi: 10.7861/clinmed.2019-coron

2. World Health Organization. Rolling updates on coronavirus disease (COVID-19). [cited 2020 Sep 3]. Available at: https://www.who.int/emergencies/diseases/novel-coronavirus-2019/events-as-they-happen

3. Falandry C, Filteau C, Ravot C, Le Saux O. Challenges with the management of older patients with cancer during the COVID-19 pandemic. J Geriat Oncol 2020. 11: 747-9. doi: 10.1016/j.jgo.2020.03.020

4. Liang W, Guan W, Chen R, Wang W, Li J, Xu K, et al. Cancer patients in SARSCoV-2 infection: a nationwide analysis in China. Lancet Oncol 2020; 2: 335-7. doi: 10.1016/S1470-2045(20)30096-6

5. Lung Cancer Study Group, Chinese Thoracic Society, Chinese Medical Association; Chinese Respiratory Oncology Collaboration. [Expert recommendations on the management of patients with advanced non-smal cell lung cancer during epidemic of COVID-19 (Trial version)]. [Article in Chinese]. Zhonghualie He He Hu Xi ZaZhi 2020; 43: 297-301. doi: 10.3760/ cma.j.cn112147-20200221-00138

6. Mendoza $C$, Kraemer $P$, Herrera $P$, Burdiles $P$, Sepúlveda $D$, Núñez E, et al. [Clinical guidelines using the GRADE system (Grading of recommendations assessment, development and evaluation)]. Rev Med Chil 2017; 145: 1463-70. doi: 10.4067/s0034-98872017001101463

7. Jin $\mathrm{YH}$, Cai $\mathrm{L}$, Cheng ZS, Cheng $\mathrm{H}$, Deng $\mathrm{T}$, Fan $\mathrm{YP}$, et al; for the Zhongnan Hospital of Wuhan University Novel Coronavirus Management and Research Team, Evidence-Based Medicine Chapter of China International Exchange and Promotive Association for Medical and Health Care (CPAM). A rapid advice guideline for the diagnosis and treatment of 2019 novel coronavirus (2019-nCoV) infected pneumonia (standard version). Mil Med Res 2020; 7: 4. doi: 10.1186/s40779-020-0233-6
8. Rubin GD, Ryerson CJ, Haramati LB, Sverzellati N, Kanne JP, Raoof S, et al. The role of chest imaging in patient management during the COVID-19 pandemic: a multinational consensus statement from the Fleischner Society. Chest 2020; 158: 106-16. doi: 10.1016/j.chest.2020.04.003

9. Wong HYF, Lam HYS, Fong AH, Leung ST, Chin TW, Lo CSY, et al. Frequency and distribution of chest radiographic findings in COVID-19 positive patients. Radiology 2020; 296: E72-8. doi: 10.1148/radiol.2020201160

10. Italian Society of Radiology - SIRM. Covid-19 database. [cited 2020 Oct 25]. Available at: https://www.sirm.org

11. Peng QY, Wang XT, Zhang LN, Chinese Critical Care Ultrasound Study Group (CCUSG). Findings of lung ultrasonography of novel corona virus pneumonia during the 2019-2020 epidemic. Intensive Care Med 2020; 46: 849-50. doi: $10.1007 / \mathrm{s} 00134-020-05996-6$

12. See KC, Ong V, Tan YL, Sahagun J, Taculod J. Chest radiography versus lung ultrasound for identification of acute respiratory distress syndrome: a retrospective observational study. Crit Care 2018; 22: 1-9. doi: 10.1186/ s13054-018-2105-y

13. Mizumoto K, Kagaya K, Zarebski A, Chowell G. Estimating the asymptomatic proportion of coronavirus disease 2019 (COVID-19) cases on board the Diamond Princess cruise ship, Yokohama, Japan, 2020. Euro Surveill 2020; 25: 2000180. doi: 10.2807/1560-7917.ES.2020.25.10.2000180

14. Nishiura H, Kobayashi T, Miyama T, Suzuki A, Jung SM, Hayashi K, et al. Estimation of the asymptomatic ratio of novel coronavirus infections (COVID-19). Int J Infect Dis 2020; 94: 154-55. doi: 10.1016/j.ijid.2020.03.020

15. Li R, Pei S, Chen B, Song Y, Zhang T, Yang W, et al. Substantial undocumented infection facilitates the rapid dissemination of novel coronavirus (SARSCoV2). Science 2020; 368: 489-93. doi: 10.1126/science.abb3221

16. Zhou P, Yang XL, Wang XG, Hu B, Zhang L, Zhang W, et al. A pneumonia outbreak associated with a new coronavirus of probable bat origin. Nature 2020; 579: 270-3. doi: 10.1038/s41586-020-2012-7

17. Center for Disease Control and Prevention. Interim U.S. Guidance for risk assessment and public health management of healthcare personnel with potential exposure in a healthcare setting to patients with coronavirus disease (COVID-19); 2020. [cited 2020 Apr 01]. Available at: https://www. cdc.gov/coronavirus/2019-ncov/hcp/guidance-risk-assesment-hcp.htm

18. Center for Disease Control and Prevention. Coronavirus disease 2019 (COVID-19) public health recommendations for community-Related exposure; 2020. [cited $2020 \mathrm{Apr}$ 01]. Available at: https://www.cdc.gov/ coronavirus/2019-ncov/php/public-health-recommendations.htm

19. Kooraki S, Hosseiny M, Myers L, Gholamrezanezhad A. Coronavirus (COVID-19) outbreak: what the department of radiology should know. J Am Coll Radiol 2020; 17: 447-51. doi: 10.1016/j.jacr.2020.02.008

20. Belfiore MP, Urraro F, Grassi R, Giacobbe G, Patelli G, Cappabianca S, et al. Artificial intelligence to codify lung CT in Covid-19 patients. Radiol Med 2020; 125: 500-4. doi: 10.1007/s11547-020-01195-x

21. Borghesi A, Zigliani A, Masciullo R, Golemi S, Maculotti P, Farina D, et al Radiographic severity index in COVID-19 pneumonia: relationship to age and sex in 783 Italian patients. Radiol Med 2020; 125: 461-4. doi: 10.1007/ s11547-020-01202-1

22. Borghesi A, Maroldi R. COVID-19 outbreak in Italy: experimental chest X-ray scoring system for quantifying and monitoring disease progression. Radio Med 2020; 125: 509-13 doi: $10.1007 /$ s11547-020-01200-3

23. Fichera G, Stramare R, De Conti G, Motta R, Giraudo C. It's not over until it's over: the chameleonic behaviour of COVID-19 over a six-day period. Radio Med 2020; 125: 514-6. doi: 10.1007/s11547-020-01203-0

24. Neri E, Miele V, Coppola F, Grassi R. Use of CT and artificial intelligence in suspected or COVID-19 positive patients: statement of the Italian Society of Medical and Interventional Radiology. Radiol Med 2020; 125: 505-8. doi: 10.1007/s11547-020-01197-9

25. Agostini A, Floridi C, Borgheresi A, Badaloni M, Esposto Pirani P, Terilli $F_{,}$ et al. Proposal of a low-dose, long-pitch, dual-source chest CT protocol on third-generation dual-source CT using a tin filter for spectral shaping at 100 kVp for Corona Virus Disease 2019 (COVID-19) patients: a feasibility study. Radiol Med 2020; 125: 365-73. doi: 10.1007/s11547-020-01179-x

26. Giovagnoni A. Facing the COVID-19 emergency: we can and we do. Radiol Med 2020; 125: 337-8. doi: 10.1007/s11547-020-01178-y 
27. Pediconi F, Galati F, Bernardi D, Belli P, Brancato B, Calabrese M, et al. Breast imaging and cancer diagnosis during the COVID-19 pandemic: recommendations from the Italian College of Breast Radiologists by SIRM. Radiol Med 2020; 125: 926-30. doi: 10.1007/s11547-020-01254-3

28. Neri E, Miele V, Coppola F, Grassi R. Use of CT and artificial intelligence in suspected or COVID-19 positive patients: statement of the Italian Society of Medical and Interventional Radiology. Radiol Med 2020; 125: 505-8. doi:10.1007/s11547-020-01197-9

29. Neri E, Coppola F, Larici AR, Sverzellati N, Mazzei MA, Sacco P, et al. Structured reporting of chest CT in COVID-19 pneumonia: a consensus proposal. Insights Imaging 2020; 11: 92. doi: 10.1186/s13244-020-00901-7

30. Byrne D, O'Neill SB, Müller NL, Jalal S, Parker W, Nicolaou S, et al. RSNA Expert consensus Statement on reporting chest CT findings related to COVID-19: interobserver agreement between chest radiologists. Can Assoc Radiol J 2020, Jul 2; 846537120938328. [Ahead of print]. doi:10.1177/0846537120938328

31. Huang Z, Zhao S, Li Z, Chen W, Zhao L, Deng L, et al. The battle against coronavirus disease 2019 (COVID-19): emergency management and infection control in a radiology department. J AmColl Radiol 2020; 17: 710-6. doi: 10.1016/j.jacr.2020.03.011

32. Rubin GD, Ryerson CJ, Haramati LB, Sverzellati N, Kanne JP, Raoof S, et al. The role of chest imaging in patient management during the COVID-19 pandemic: a multinational consensus statement from the Fleischner Society. Radiology 2020; 296: 172-80. doi: 10.1148/radiol.2020201365

33. Albano D, Bruno A, Bruno F, Calandri M, Caruso D, Clemente A, et al. Impact of coronavirus disease 2019 (COVID-19) emergency on Italian radiologists: a national survey. Eur Radiol 2020; 30: 6635-44. 1-10. doi: 10.1007/s00330020-07046-7

34. Belfiore MP, Urraro F, Grassi R, Giacobbe G, Patelli G, Cappabianca S, et al. Artificial intelligence to codify lung CT in Covid-19 patients. Radiol Med 2020; 125: 500-4. doi: 10.1007/s11547-020-01195-x

35. Laghi A, Grassi R. Italian radiology's response to the COVID-19 outbreak. J Am Coll Radiol 2020; 17: 699-700. doi: 10.1016/j.jacr.2020.04.012

36. Duggan NM, Liteplo AS, Shokoohi H, Goldsmith AJ. Using lung point-ofcare ultrasound in suspected COVID-19: case series and proposed triage algorithm. Clin Pract Cases Emerg Med 2020; 4: 289-94. doi: 10.5811/ cpcem.2020.7.47912

37. Di Serafino M, Notaro M, Rea G, lacobellis F, PaoliVD, Acampora C, et al. The lung ultrasound: facts or artifacts? In the era of COVID-19 outbreak. Radiol Med 2020; 125: 738-53. doi: 10.1007/s11547-020-01236-5

38. Alilio PM, Ebeling-Koning NE, Roth KR, Desai T. Lung point-of-care (POCUS) ultrasound in a pediatric COVID-19 case. Radiol Case Rep 2020; 15: 2314-8. doi: 10.1016/j.radcr.2020.09.007

39. Shen C, Yu N, Cai S, Zhou J, Sheng J, Liu K, et al. Evaluation of dynamic lung changes during coronavirus disease 2019 (COVID-19) by quantitative computed tomography. J Xray Sci Technol 2020; 28: 863-73. doi: 10.3233/ XST-200721

40. Pakdemirli E, Mandalia U, Monib S. Characteristics of chest CT images in patients with COVID-19 pneumonia in London, UK. Cureus 2020; 12: e10289. doi: 10.7759/cureus.10289

41. Gatti $M$, Calandri $M$, Barba $M$, Biondo A Geninatti $C$, Gentile $S$, et al. Baseline chest X-ray in coronavirus disease 19 (COVID-19) patients: association with clinical and laboratory data. Radiol Med 2020; 125; 1271-9. doi: $10.1007 /$ s11547-020-01272-1

42. Giannitto C, Sposta FM, Repici A, Vatteroni G, Casiraghi E, Casari E, et al. Chest CT in patients with a moderate or high pretest probability of COVID-19 and negative swab. Radiol Med 2020; 125: 1260-70. doi:10.1007/ s11547-020-01269-w

43. Cartocci G, Colaiacomo MC, Lanciotti S, Andreoli C, De Cicco ML, Brachetti $\mathrm{G}$, et al. Chest CT for early detection and management of coronavirus disease (COVID-19): a report of 314 patients admitted to emergency department with suspected pneumonia. Radiol Med 2020; 125: 931-42. doi: 10.1007/s11547-020-01256-1

44. lerardi AM, Wood BJ, Arrichiello A, Bottino N, Bracchi L, Forzenigo L, et al. Preparation of a radiology department in an Italian hospital dedicated to COVID-19 patients. Radiol Med 2020; 125: 894-901. doi: 10.1007/s11547020-01248-1
45. Cozzi D, Albanesi M, Cavigli E, Moroni C, Bindi A, Luvarà S, et al. Chest X-ray in new coronavirus disease 2019 (COVID-19) infection: findings and correlation with clinical outcome. Radiol Med 2020; 125: 730-7. doi: 10.1007/ s11547-020-01232-9

46. Rawashdeh MA, Saade C. Radiation dose reduction considerations and imaging patterns of ground glass opacities in coronavirus: risk of over exposure in computed tomography. Radiol Med 2020, Sep 8; [Ahead of print]. doi:10.1007/s11547-020-01271-2

47. Larici AR, Cicchetti G, Marano R, Merlino B, Elia L, Calandriello L, et al. Multimodality imaging of COVID-19 pneumonia: from diagnosis to followup. A comprehensive review. Eur J Radiol 2020; 131: 109217. doi: 10.1016/j. ejrad.2020.109217

48. Carlos RC, Lowry KP, Sadigh G. The coronavirus disease 2019 (COVID-19) pandemic: a patient-centered model of systemic shock and cancer care adherence. J Am Coll Radiol 2020; 17: 927-30. doi: 10.1016/j.jacr.2020.05.032 